\title{
A novel formula for graft weight estimation from preoperative computed tomography volumetric measurement in living donor liver transplantation
}

Talaat Zakareya ${ }^{1}$, Mohamed Abbasy ${ }^{1 *}$, Wael Abdel-Razek${ }^{1}$, Ibrahim Abdelkader Salama² and Mohamed Deif ${ }^{3}$

*Correspondence: mabbasy@liver-eg.org

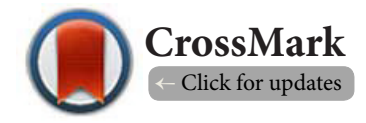

'Departments of Hepatology, National Liver Institute, Menoufiya University, Shebeen El-Kom, Egypt.

${ }^{2}$ Departments of Hepatobiliary Surgery, National Liver Institute, Menoufiya University, Shebeen El-Kom, Egypt.

${ }^{3}$ Departments of Radiology, National Liver Institute, Menoufiya University, Shebeen El-Kom, Egypt.

\begin{abstract}
Background: Computed tomography $(\mathrm{CT})$ is the current gold standard for preoperative assessment of graft volume in the context of living donor liver transplantation (LDLT) despite the commonly noted mismatch between CT estimated graft volume (CT-GV) and actual graft weight (AGW).

Aim: to find a formula that correlates preoperative virtual CT graft volume with AGW measured on the back table.

Methods: CT volumetric data as well as AGW of 125 consecutive living liver donors in the period between 2010 and 2016 were reviewed. Correlation between CT-GV and AGW was done. Formula for line of best fit was obtained by plotting CT-GV against AGW for right and left lobes using linear regression analysis.

$\underline{\text { Results: }}$ One hundred and nineteen living donors had complete data allowing downstream analysis.

Donors were mostly males $(59.7 \%)$ with mean age of $28.4 \pm 6.7$ years. Ninety-seven of them $(81.5 \%)$ donated right lobe while $22(18.5 \%)$ left lobe grafts. Mean CT-GV was $870.0 \pm 142.9 \mathrm{ml}$ for right lobe grafts and $335.5 \pm 112.1 \mathrm{ml}$ for left lobe grafts. Mean AGW was $851.7 \pm 162.9 \mathrm{~g}$ for right lobe grafts and $296.2 \pm 74.5 \mathrm{~g}$ for left lobe grafts. The following formulae were derived to calculate AGW $(\mathrm{g})$ : [0.92xCT-GV $(\mathrm{ml})+51.48$; $\left.\mathrm{R}^{2}=0.651, \mathrm{P}<0.0001\right]$ and $\left.\left[0.53 \times C T-G V(\mathrm{ml})+120 ; \mathrm{R}^{2}=0.625, \mathrm{P}<0.0001\right)\right]$ for the right and left lobe grafts respectively.
\end{abstract}

Conclusion: We postulate reliable formulae to convert virtual CT-GV into AGW, to accurately correct the discrepancy between preoperative CT-GV and AGW in the setting of LDLT.

Keywords: Graft weight, CT volumetry, living donor liver transplantation

\section{Introduction}

Living donor liver transplantation (LDLT) is a lifesaving alternative to deceased donor liver transplantation (DDLT) for patients with end stage liver disease. Best matching between graft size and recipient weight is crucial to avert small for size syndrome and its serious complications. Liver represents approximately $2 \%$ of the total body weight and liver graft required to meet metabolic demands should be $40-50 \%$ of liver weight which in parallel equals $0.8-1 \%$ of the recipient's weight. This lead to the concept that graft to recipient weight ratio (GRWR) should be at least $0.8 \%$ for successful liver transplantation [1-9]. To obtain the desired GRWR of $0.8 \%$ or more, accurate estimation of graft weight is required. Whenever left lobe graft meets the required GRWR then it will be preferable to use because of easier surgical technique and lower donor morbidity when compared to right lobe hepatectomy. Therefore, graft weight estimation will demarcate the decision whether right or left lobe graft will be used [10].

Computed tomography (CT) is the gold standard modality for preoperative assessment of the liver volume worldwide and has a paramount yield in the prediction of graft weight in the setting of LDLT [11,12]. 
The concept that density of liver tissue is equal to that of water was widely accepted in the past decades till recently [5,14-18]. This concept was reported by Van Thiel et al. in 1985, where he demonstrated a close correlation between liver weight and volume of water at $25^{\circ} \mathrm{C}$. Since then, liver volume in milliliters was equated to liver weight in grams on a one to one basis [13]. Despite that, discrepancy between liver volume assessed preoperatively by $\mathrm{CT}$ and actual liver weight has been commonly reported making this concept disputable and it became questionable whether 1 milliliter of liver volume actually weighs 1 gram [19-21].

In the current study, we tried to find a correlation formula between preoperative CT estimated graft volume (CT-GV) and actual graft weight (AGW) to overcome this mismatching and avoid unanticipated small grafts with the subsequent negative impact on liver transplantation outcome.

\section{Patients and methods}

Data of 125 consecutive living liver donors in the period between 2010 and 2016 in the liver transplantation center at the National Liver Institute, Shebeen El-Kom, Egypt, were reviewed. CT-based volumetric data as well as back table actual graft weight were recorded for each donor. Donors with missed volumetric and/or actual graft weight data were excluded.

CT-based liver volume assessment was achieved by scanning the studied populations at $5-\mathrm{mm}$ intervals using the 20-slice multidetector CT (Somatom Definition AS, Siemens, Germany). Liver outlinings were performed by a single operator well trained to recognize the relevant organ boundaries. Inferior vena cava, extra-parenchymal portal vein and the gall bladder were excluded from the outline. Hepatic veins and intra-parenchymal portal venous system and the fissures that did not open into the abdominal cavity were included in the outlining [22]. Volume was determined in milliliters using the automatic volumetry software of Intellispace Portal (Philips Healthcare, Best, The Netherlands).

Partial hepatic resection for donation was performed guided by the preoperatively imaged cutting plane. A preservation solution; histidine-tryptophan-ketoglutarate (HTK) was used to flush the graft immediately after hepatectomy. An automatic weighing machine was used to measure the actual graft weight after being drained from the preservation solution.

\section{Statistical methods}

Statistical analyses were performed with SPSS version 22 for Mac (IBM Corp., Armonk, NY, USA). Continuous numeric variables were expressed as mean and standard deviation (SD). Correlation formula for line of best fit was obtained by plotting CT-GV against AGW using linear regression analysis. The statistical significance was set at $\mathrm{P}$-value of less than 0.05 for all tests.

\section{Results}

One hundred and nineteen out of 125 donors had complete data allowing downstream analysis. The characteristics of the studied donors are shown in Table 1. Most of them were males $(n=71,59.7 \%)$ with a mean age of $28.4 \pm 6.7$ years. Right lobe donors were 97 (81.5\%) and left lobe donors were 22 (18.5\%).

CT-GV ranged from 627.2 to $1319.5 \mathrm{ml}$ with a mean of $870.0 \pm 142.9 \mathrm{ml}$ for right lobe grafts while it ranged from 217.8 to $613.4 \mathrm{ml}$ with a mean of $335.5 \pm 112.1 \mathrm{ml}$ for left lobe grafts. The range and mean of AGW (g) were 500-1250, 851.7 \pm 162.9 ; 200-450, 296.2 \pm 74.5 for right and left lobe grafts respectively.

The relationship between CT-GV and AGW was significantly linear for both right $\left(Y=0.92 X+51.48 ; R^{2}=0.651, P<0.0001\right)$ (Figure 1) and left lobe grafts $\left(Y=0.53 X+120 ; R^{2}=0.625, P<0.0001\right)$ (Figure 2).

Therefore, AGW could be accurately calculated from preoperative CT-GV using the following formulae [AGW $(\mathrm{g})=$ $0.92 \times C T-G V(m l)+51.48$ ] for the right lobe grafts and [AGW $(\mathrm{g})=0.53 \times \mathrm{CT}-\mathrm{GV}(\mathrm{ml})+120]$ for left lobe grafts.

\section{Discussion}

Although CT volumetry has an acceptable accuracy in the preoperative estimation of the actual liver volume, the anticipated graft weight on the basis of one milliliterof liver volume equals one gram of liver weight has some discrepancy [14-16]. This concept has been criticized being derived from measurements of cirrhotic livers [20].

Altogether with difference in density and debatable one to one basis, other factors could contribute to the discrepancy between CT estimated graft volume and AGW including CT pitfalls, variations in CT machine and softwares of volume

Table 1. Characteristics of the studied donors.

\begin{tabular}{ll}
\hline Age in years (mean \pm SD) & $\mathbf{2 8 . 4} \pm \mathbf{6 . 7}$ \\
\hline Gender & $71(59.7)$ \\
$\quad$ Males, $\mathrm{n}(\%)$ & $48(40.3)$ \\
$\quad$ Females, $\mathrm{n}(\%)$ & $97(81.5)$ \\
\hline Graft type & $22(18.5)$ \\
$\quad$ Right lobe, $\mathrm{n}(\%)$ & \\
$\quad$ Left lobe, $\mathrm{n}(\%)$ & $627.2-1319.5$ \\
\hline CT-GV of right lobe grafts (ml) & $870.0 \pm 142.9$ \\
$\quad$ Range & \\
$\quad$ Mean \pm SD & $217.8-613.4$ \\
\hline CT-GV of left lobe grafts (ml) & $335.5 \pm 112.1$ \\
$\quad$ Range & \\
$\quad$ Mean $\pm S D$ & $500-1250$ \\
\hline AGW of right lobe grafts (g) & $851.7 \pm 162.9$ \\
$\quad$ Range & \\
$\quad$ Mean $\pm S D$ & $200-450$ \\
\hline AGW of left lobe grafts (g) & $296.2 \pm 74.5$ \\
Range & \\
Mean $\pm S D$ & \\
\hline AGW, Actual graft weight; CT-GV, CT-estimated \\
graft volume; SD, Standard deviation.
\end{tabular}




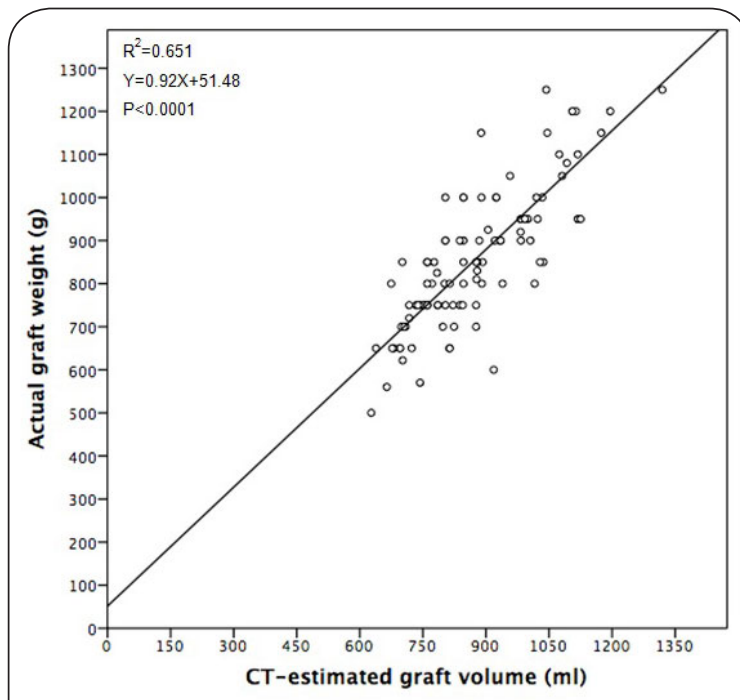

Figure 1. Correlation between CT-estimated graft volume $(\mathrm{ml})$ and actual graft weight $(\mathrm{g})$ in right lobe grafts.

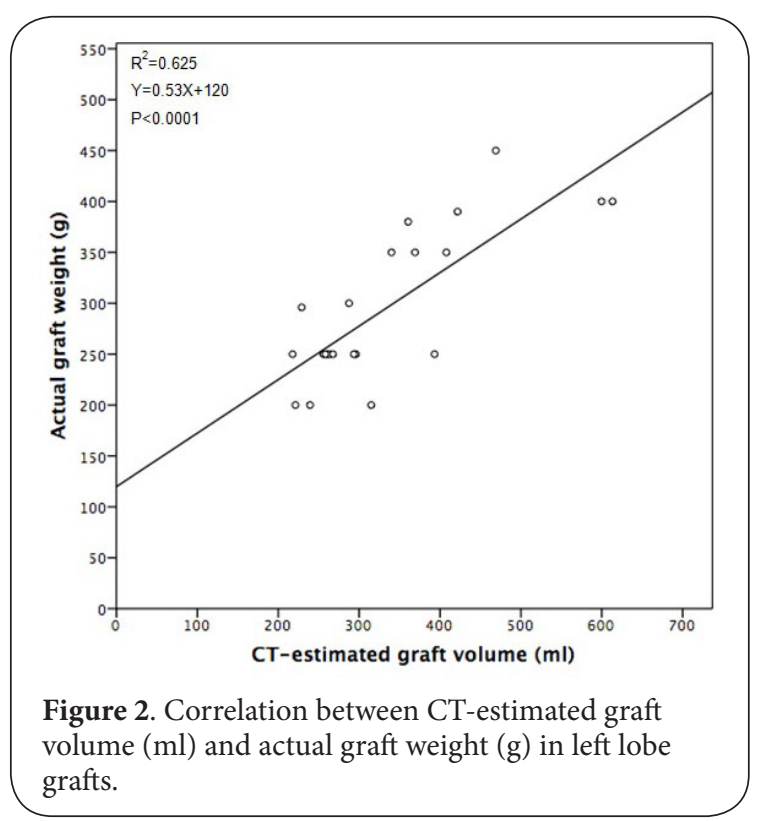

calculation, inter-observer variations, deviation from the virtual preoperative cutting plane, variability of steatosis and level of hydration at the time of the scanning, gender related variation of liver density and finally difference when scanning a liver perfused with blood and when flushed with preservation solutions $[\mathbf{1 7}, \mathbf{1 8}]$.

An error ratio of \pm 5 to $\pm 20 \%$ has been reported when using preoperative CT volumetry for estimation of graft weight [23]. However, most of liver transplantation centers accept this error ratio and few only have interested in finding a way to correct the estimated graft weight derived from CT volumetric measurement in an attempt to make matching between CT volumetric measurement and AGW as close as feasible $[17,20,21]$.

In the current study, a correlation formula of $[A G W(g)=0.92 x$ CT-GV ( $\mathrm{ml})+51.48]$ has been derived to obtain AGW from preoperative $C T$ volumetric measurements for right lobe grafts $\left(R^{2}=0.651, P<0.0001\right)$ and $[A G W(g)=0.53 \times C T-G V(m l)+120]$ for left lobe grafts $\left(R^{2}=0.625, P<0.0001\right)$. It is noteworthy that the slope was higher in the formula of right lobe grafts [0.92, standard error (SE): 0.069] compared to that of the left lobe (0.53, SE: 0.091). This indicates that, when considering the slope, for each $1 \mathrm{ml}$ increase in CT volumetric measurement, a $0.39 \mathrm{~g}$ higher increase of AGW would be predicted in right lobe grafts. On the other hand, the intercept was higher in the formula of left (120, SE: 32.2) compared to right (51.48, SE: 60.89) lobe grafts. This reflects a $68.52 \mathrm{~g}$ higher baseline AGW to be expected in left lobe grafts when CT volumetric reading theoretically equals zero $\mathrm{ml}$. This difference in slope and intercept could be explained by the small sample size of the left lobe grafts $(n=22)$.

Yoneyama et al. reported that healthy or non-cirrhotic liver seems to be lighter than cirrhotic liver and postulated that 1 milliliter of liver volume equates 0.85 gram of liver tissue and derived a coefficient factor for weight per volume of 0.84 in right lobe grafts $\left(R^{2}=0.52, P<0.01\right)$ and 0.85 in left lobe grafts $\left(R^{2}=0.82, P<0.01\right)$ [20].

Another correction formula has been described by Lui and his group with good accuracy in predicting graft weight from preoperative CT volumetry as follows: Graft Weight $(\mathrm{g})=$ $0.86 \times C T$ volume $(\mathrm{ml})+72.5\left(\mathrm{R}^{2}=0.9\right)[21]$.

Our hypothesis is that, a given formula of one center might be inconvenient to the others because of the previously mentioned factors.

\section{Conclusion}

In our donors, the best-fit formulae for accurate estimation of the AGW $(\mathrm{g})$ of the right and left lobe grafts from the preoperative CT volumetry were $[0.92 \times C T-G V(m l)+51.48]$ and [0.53xCT-GV $(\mathrm{ml})+120]$ respectively.

\section{Competing interests}

The authors declare that they have no competing interests.

Authors' contributions

\begin{tabular}{|l|c|c|c|c|c|}
\hline Authors' contributions & TZ & MA & WAR & IAS & MD \\
\hline Research concept and design & $\checkmark$ & $\checkmark$ & -- & -- & -- \\
\hline Collection and/or assembly of data & $\checkmark$ & $\checkmark$ & -- & $\checkmark$ & $\checkmark$ \\
\hline Data analysis and interpretation & $\checkmark$ & $\checkmark$ & $\checkmark$ & -- & $\checkmark$ \\
\hline Writing the article & $\checkmark$ & $\checkmark$ & -- & -- & $\checkmark$ \\
\hline Critical revision of the article & $\checkmark$ & $\checkmark$ & $\checkmark$ & -- & -- \\
\hline Final approval of article & $\checkmark$ & $\checkmark$ & $\checkmark$ & $\checkmark$ & $\checkmark$ \\
\hline Statistical analysis & $\checkmark$ & -- & $\checkmark$ & -- & -- \\
\hline
\end{tabular}

\section{Acknowledgement}

Liver transplantation unite, National Liver Institute, Menoufiya University. 
Zakareya et al., Transplantation Technology 2017,

http://www.hoajonline.com/journals/pdf/2053-6623-5-1.pdf

doi: $10.7243 / 2053-6623-5-1$

\section{Publication history}

Senior Editor: Henk Jan Schuurman, University of Minnesota, USA.

Received: 22-Apr-2017 Final Revised: 16-May-2017

Accepted: 22-Jun-2017 Published: 02-Jul-2017

\section{References}

1. Kiuchi T, Kasahara $\mathrm{M}$, Uryuhara $\mathrm{K}$, Inomata $\mathrm{Y}$, Uemoto $\mathrm{S}$, Asonuma K, Egawa H, Fujita S, Hayashi M and Tanaka K. Impact of graft size mismatching on graft prognosis in liver transplantation from living donors. Transplantation. 1999; 67:321-7. | Article | PubMed

2. Shoup $M$, Gonen $M$, D'Angelica $M$, Jarnagin WR, DeMatteo RP, Schwartz $\mathrm{LH}$, Tuorto $\mathrm{S}$, Blumgart $\mathrm{LH}$ and Fong $\mathrm{Y}$. Volumetric analysis predicts hepatic dysfunction in patients undergoing major liver resection. $J$ Gastrointest Surg. 2003; 7:325-30. | PubMed

3. Kawasaki S, Makuuchi M, Matsunami H, Hashikura Y, Ikegami T, Chisuwa $\mathrm{H}$, Ikeno T, Noike T, Takayama T and Kawarazaki H. Preoperative measurement of segmental liver volume of donors for living related liver transplantation. Hepatology. 1993; 18:1115-20. | Article | PubMed

4. Emond $J C$ and Leib $M$. The living-related liver transplant evaluation: linking risk factors and outcome. Liver Transp/ Surg. 1996; 2:57-63. | Article | PubMed

5. Urata K, Kawasaki S, Matsunami H, Hashikura Y, Ikegami T, Ishizone S, Momose Y, Komiyama A and Makuuchi M. Calculation of child and adult standard liver volume for liver transplantation. Hepatology. 1995; 21:1317-21. | Article | PubMed

6. Tanaka K and Ogura Y. "Small-for-size graft" and "small-for-size syndrome" in living donor liver transplantation. Yonsei Med J. 2004; 45:1089-94. | Article | PubMed

7. Sakamoto S, Uemoto S, Uryuhara K, Kim I, Kiuchi T, Egawa H, Inomata $Y$ and Tanaka K. Graft size assessment and analysis of donors for living donor liver transplantation using right lobe. Transplantation. 2001; 71:1407-13. | Article | PubMed

8. Ben-Haim M, Emre S, Fishbein TM, Sheiner PA, Bodian CA, Kim-Schluger L, Schwartz ME and Miller CM. Critical graft size in adult-to-adult living donor liver transplantation: impact of the recipient's disease. Liver Transpl. 2001; 7:948-53. | Article | PubMed

9. Lo CM, Fan ST, Liu CL, Chan JK, Lam BK, Lau GK, Wei WI and Wong J. Minimum graft size for successful living donor liver transplantation. Transplantation. 1999; 68:1112-6. | Article | PubMed

10. Sudhindran S, Menon RN and Balakrishnan D. Challenges and Outcome of Left-lobe Liver Transplants in Adult Living Donor Liver Transplants. J Clin Exp Hepatol. 2012; 2:181-7. | Article | PubMed Abstract | PubMed FullText

11. Schiano TD, Bodian C, Schwartz ME, Glajchen N and Min AD. Accuracy and significance of computed tomographic scan assessment of hepatic volume in patients undergoing liver transplantation. Transplantation. 2000; 69:545-50. | Article | PubMed

12. Tanpowpong N, Yimpraphan S, Vajragupta L, Sirijindakul B and Nunthasoot B. Accuracy of liver volume measurement using multidetector computed tomography. Asian Biomed. 2007; 1:415-20.

13. Van Thiel DH, Hagler NG, Schade RR, Skolnick ML, Heyl AP, Rosenblum E, Gavaler JS and Penkrot RJ. In vivo hepatic volume determination using sonography and computed tomography. Validation and a comparison of the two techniques. Gastroenterology. 1985; 88:1812-7. | Article | PubMed

14. Kamel IR, Kruskal JB, Warmbrand G, Goldberg SN, Pomfret EA and Raptopoulos V. Accuracy of volumetric measurements after virtual right hepatectomy in potential donors undergoing living adult liver transplantation. AJR Am J Roentgenol. 2001; 176:483-7. | Article | PubMed

15. Harada N, Shimada M, Yoshizumi T, Suehiro T, Soejima Y and Maehara Y. A simple and accurate formula to estimate left hepatic graft volume in living-donor adult liver transplantation. Transplantation. 2004; 77:15715. | Article | PubMed
16. Salvalaggio PR, Baker TB, Koffron AJ, Fryer JP, Clark L, Superina RA, Blei AT, Nemcek A and Abecassis MM. Liver graft volume estimation in $\mathbf{1 0 0}$ living donors: measure twice, cut once. Transplantation. 2005; 80:11815. | Article | PubMed

17. Hwang S, Lee SG, Kim KH, Park KM, Ahn CS, Moon DB, Chu CW, Lee YJ and Min PC. Correlation of blood-free graft weight and volumetric graft volume by an analysis of blood content in living donor liver grafts. Transplant Proc. 2002; 34:3293-4. | Article | PubMed

18. Lemke AJ, Brinkmann MJ, Pascher A, Steinmuller T, Settmacher U, Neuhaus $P$ and Felix R. [Accuracy of the CT-estimated weight of the right hepatic lobe prior to living related liver donation (LRLD) for predicting the intraoperatively measured weight of the graft]. Rofo. 2003; 175:1232-8. | Article | PubMed

19. Chan SC, Liu CL, Lo CM, Lam BK, Lee EW, Wong Y and Fan ST. Estimating liver weight of adults by body weight and gender. World J Gastroenterol. 2006; 12:2217-22. | Article | PubMed Abstract | PubMed FullText

20. Yoneyama T, Asonuma K, Okajima H, Lee KJ, Yamamoto H, Takeichi T, Nakayama $Y$ and Inomata $Y$. Coefficient factor for graft weight estimation from preoperative computed tomography volumetry in living donor liver transplantation. Liver Transpl. 2011; 17:369-72. | Article | PubMed

21. Lui SA, Bonney GK and Kow WCA et al. Standard Formulae in Predicting Liver Volumes: A South East Asian Series of Adult Living Donors. J Transplant Technol Res. 2016; 6:153. | Article

22. Geraghty EM, Boone JM, McGahan JP and Jain K. Normal organ volume assessment from abdominal CT. Abdom Imaging. 2004; 29:482-90. | Article I PubMed

23. Lemke AJ, Brinkmann MJ, Schott T, Niehues SM, Settmacher U, Neuhaus $\mathrm{P}$ and Felix R. Living donor right liver lobes: preoperative $\mathrm{CT}$ volumetric measurement for calculation of intraoperative weight and volume. Radiology. 2006; 240:736-42. | Article | PubMed

\section{Citation:}

Zakareya T, Abbasy M, Abdel-Razek W, Abdelkader Salama I and Deif M. A novel formula for graft weight estimation from preoperative computed tomography volumetric measurement in living donor liver transplantation. Transplant Technol. 2017; 5:1. http://dx.doi.org/10.7243/2053-6623-5-1 